\title{
Effect of Scaffolding in the Assessment of Engineering Practices for Middle School Students (Fundamental)
}

Debra Brockway, Educational Testing Service

Ms. Brockway is a Senior Research Associate at Educational Testing Service (ETS) in Princeton, NJ, where she leads and contributes to projects exploring innovative approaches to assessment and integrating the STEM subjects.

Mr. Kofi James 


\section{Effect of Scaffolding in the Assessment of Engineering Practices for Middle School Students (Fundamental)}

\section{Introduction}

Scaffolding is often used to facilitate learning by providing supports that allow students to complete tasks that they would not otherwise be able to complete successfully. The research literature on the types and efficacy of scaffolding in the context of teaching and learning is extensive. Although there are numerous examples of scaffolding in large scale assessment, there is relatively little research related to the impact of scaffolding in this context. With the need to create large-scale assessments aligned to the Next Generation Science Standards, which requires assessing the integration of science and engineering core ideas with practices, knowledge about the impact of scaffolding in assessment tasks on the measurement of students' knowledge and abilities may have increased importance. We conducted a study using cognitive interviews and classroom data to compare student responses and performance in scaffolded and unscaffolded versions of two tasks that integrate engineering practices with science. The two versions elicited different types of information about students' abilities that may inform assessment design and development. We also found significant differences between overall performance on the two versions and between the two settings in which the instrument was administered.

\section{Background}

Aspects of technology and engineering have appeared in some K-12 science classrooms and, to a limited extent, in prior national science standards, but the Next Generation Science Standards (NGSS) present a true integration of science, engineering and technology [1]. This is a new approach to teaching science that will require new curriculum materials, professional development and other supports for teachers, and new assessments [2]. Assessments aligned to the NGSS are expected to require students to draw upon an understanding of core ideas in science and cross-cutting concepts while engaging in engineering and science practices. Current assessments were not designed to accomplish these goals and cannot easily be modified to meet this expectation [3]. These new assessment requirements present challenges on many levels including the development of complex tasks that integrate the three dimensions and that are both equitable for a wide range of students and cost-effective [3], [4]. Assessments that measure complex tasks shift the balance of response formats away from multiple-choice toward constructed-response formats and performance tasks and, as a result, the cost associated with scoring the assessments skyrockets [5]. This cost factor is evident whether human or automated approaches are used for scoring [6]. One assessment development approach that seems to have potential for moderating the cost factor in administering and scoring these complex tasks as well as supporting the assessment of students at a wide range of abilities is scaffolding.

Pea [7] describes the broadening of the concept of scaffolding over time; the different interpretations that have been espoused by researchers and practitioners; and its many manifestations across educational settings. The earliest uses of the term, and perhaps most suitable for our purposes, refer to scaffolding as supports provided to students that allow them to complete a task that they would otherwise not be able to complete successfully [8]. One type of scaffolding, channeling, reduces the degrees of freedom allowed in a task, thereby increasing the likelihood that the student's action or response is effective [7]. Scaffolding is most often described in learning contexts [9], [10], [11], [12], [13] and it has been shown to result in 
improvements in students' evidence-based explanations and argumentation [9], [13]. These are both important practices in science and engineering [14]. We have drawn upon the research literature in science education to support this work due to the limited available evidence about engineering at the K-12 level and the similarities between science and engineering practices at this level that would be likely targets for scaffolding.

There is much less evidence in the literature regarding the use of scaffolding in summative assessments. The BioKIDS project classroom assessments that Mislevy and Haertel describe [15] include varying degrees of scaffolding in tasks intended to measure students' ability to construct scientific explanations in a program that helps students learn about inquiry. Two of the tasks from that program are shown in Figure 1. The first task is more highly scaffolded than the second, channeling students to be attentive and respond in narrowly defined ways.

Quellmalz et al. [16] suggest that scaffolding has not been used in traditional large-scale, i.e. paper-based assessments, but that technology tools now afford the opportunity to do so. Although they refer to other types, the authors seem to emphasize a definition of scaffolding that is focused on adaptive testing, which is a narrower definition than what we are using here. A review of released items from the National Assessment of Educational Progress (NAEP) and Programme for International Student Assessment (PISA) large-scale assessment programs provide many examples of items in both paper-based and technology-supported assessments that would fit our definition of scaffolding, Pea's description of channeling, and are similar to the BioKIDS examples. The benefits of using scaffolding in large-scale assessment include the potential for making the assessment more equitable for a wider range of students and possibly reducing the costs associated with scoring the responses. Critiquing alternative solutions to a design problem, for example, requires the ability to draw upon science and engineering concepts and practices, including argumentation in an engineering context. Asking students to provide a recommendation regarding one or more of the alternative designs often elicits minimal responses for a variety of reasons. Without scaffolding, it is not possible to fully understand the knowledge and abilities of those students. And when students provide complete responses to such an open question, scoring can be challenging, costly, and less reliable. Adding scaffolding to such tasks by creating multiple connected items for the task can channel students' attention and responses, provide support for students and simplify scoring, but perhaps not without an expense of a different nature.

Scaffolding assessment tasks intended to measure students' engineering practices may have significant benefits, but there may be concomitant issues that impact the evidence collected about the construct of interest. Scaffolding is a variable feature of assessment tasks that affects the difficulty or focus of the task. In the BioKIDS tasks described earlier (Figure 1), the different levels of scaffolding affect the difficulty of the tasks. These tasks have been intentionally designed to provide greater support for students early in the program and to withdraw that support as students engage in more independent science investigations when they have improved their understanding of and ability to generate evidence-based explanations [15]. The Animal task assesses the narrowly-focused practices of making observations and identifying evidence while the Pond task assesses the broader practices of using a model to make a prediction and constructing an explanation, which includes making observations, stating a claim and providing evidence and reasoning. Thus, the more fine-grained practices assessed in the Animal task are subsumed within the broader practices that are assessed in the Pond task. 
Shan and Niki collected four animals from their schoolyard. They divided the animals into Group A and Group B based on their appearance as shown below:

Group A:

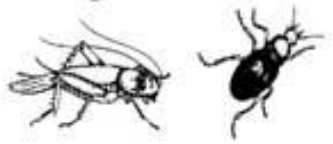

\section{Group B:}

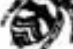

They want to place this fly

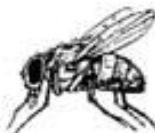
placed?

in either Group A or Group B. Where should this fly be

A fly should be in Group A/Group B

(Circle one)

Name two physical characteristics that you used when you decided to place the fly in this group:

(a)

(b)

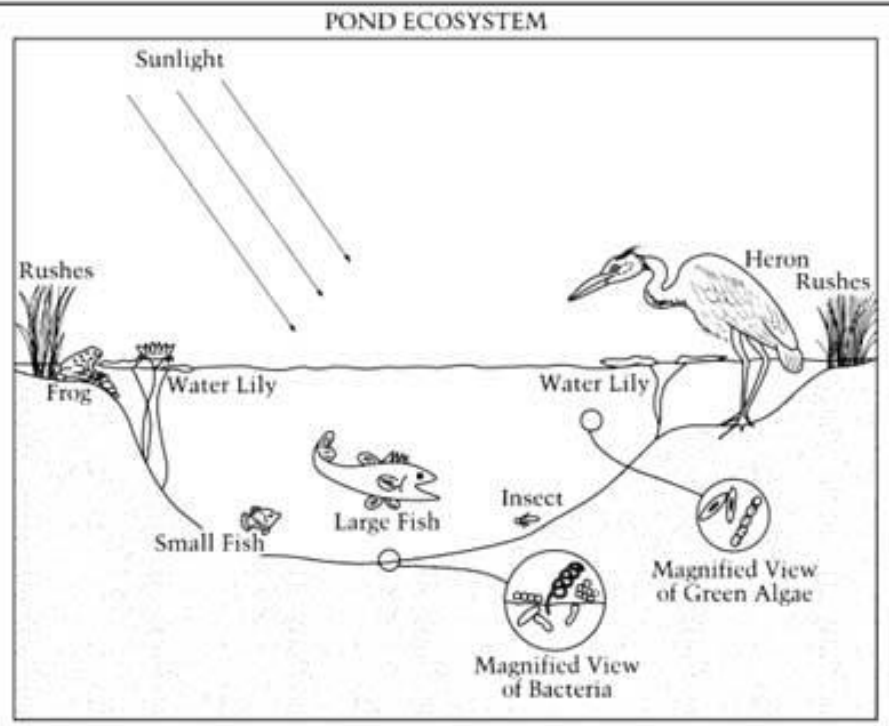

...If all of the small fish in the pond system died one year from a disease that killed only the small fish, what would happen to the algae in the pond? Explain why you think so.

What would happen to the large fish? Explain why you think so.

Figure 1: BioKIDS assessment tasks on "Formulating Scientific Explanations Using Evidence" as presented in [15]. 
Our goal in conducting this study was to explore the impact, if any, scaffolding in an assessment task has on our ability to measure the integration of engineering practices in science as described in the NGSS. Understanding how different types of scaffolding might affect the measurement of engineering and its practices is one element that will inform the development of assessments that are aligned with the NGSS. In this study we have focused on evaluating competing designs, analyzing data from tests to inform that evaluation, and engaging in argumentation in engineering contexts. The primary goal for the students in each of the tasks was to interpret the information and evidence provided to make a recommendation about the design that explicitly includes evidence to support the stance taken by the student. Taken together, these represent argumentation as described in the NGSS.

\section{Methods}

\section{Study Design and Instrument}

We conducted an exploratory study to collect student responses to two tasks administered online, one of which is the subject of this paper. The Parachute task (Parachute) was designed for students to engage in engineering and science practices by interpreting and analyzing data to evaluate alternative designs, suggesting improvements to an ineffective design, and arguing for their suggestions. We used two versions of the task. Both versions required students to evaluate five parachute designs based on data provided about the canopy diameter, suspension line length, the distance the parachute dropped and the length of time for the drop. They were told that one of the designs was ineffective, that a plastic case attached to the parachute holding a small, heavy object cracked when it landed. In both versions, students were directed to select the parachute that most likely had the ineffective design and to provide a recommendation to the group that created that design. As part of the recommendation, both versions of the task explicitly directed students to include evidence for their recommendation. (See Appendix A for screenshots of both versions of the task.) The scaffolded version of Parachute channeled students' responses for the recommendation and evidence, requiring that they select information that was presented in the task, limiting the degrees of freedom for their responses. By contrast, the primary response field for the open version of the task was a text box, allowing students complete freedom in what they attended to from the information provided in the task and their prior knowledge as well as considerably more freedom than the scaffolded task for communicating their recommendation and evidence.

The task was embedded in a larger set of science and engineering items geared toward middle-school students. Background questions regarding student demographics and experiences and classroom activities were also included in the instrument. All students received one version of Parachute for this study with the scaffolded and open versions of the task being counterbalanced in two forms of the assessment. Students were randomly assigned to version in both the cognitive interview and classroom settings. Human scoring for the free response items was conducted by project staff with two staff members coding or scoring each response. Disagreements were resolved through discussion to reach a consensus score. Qualitative analysis and descriptive statistics were used to characterize the data set. ANOVA was used to make several comparisons, including overall performance on the two versions of the task; overall performance on the open version of the task in two settings; and the length of the text responses 
in the two settings. A chi-squared test was used to determine whether the difference in the proportion of students providing evidence in the two versions is statistically significant.

\section{Participants and Data Collection}

During the 2017 school year and subsequent summer, a nonrandom sample of 137 middle-school students participated in the study. Of that total, 101 engaged in the study near the end of the school year in regularly-scheduled science classes at three New Jersey middle schools. The participating schools each have a teacher who had volunteered to participate in a related project and the data collections were combined. The schools were each paid an honorarium of $\$ 200$ for their participation. The remaining 36 students engaged in cognitive interviews that were conducted at two of the aforementioned schools and at Educational Testing Service (ETS). The students participating in the cognitive interviews at the schools were selected randomly from among all of the volunteers at each school. Those participating at ETS were recruited through an intranet site accessible to staff. All student participants in the cognitive interview study received a \$25 gift card for completing a 1-hour session. Selected demographic information for the students is shown in Table 1.

Although it appears that there is a wide grade range for the students, all of the students except for the one Grade 6 student engaged in the study just before beginning Grade 8 or near the end of that academic year. We considered excluding the data from the Grade 6 student, but found that data from this student fell well within the range of data collected overall.

Table 1: Student Demographic Information $(n=137)$

\begin{tabular}{|c|ccc|ccccc|}
\hline & \multicolumn{4}{|c|}{ Gender } & \multicolumn{5}{c|}{ Race/Ethnicity $^{\mathbf{1}}$} \\
\cline { 2 - 9 } Grade & $\mathbf{F}$ & $\mathbf{M}$ & $\begin{array}{c}\text { Other / } \\
\text { Refused }\end{array}$ & $\begin{array}{c}\text { Asian or } \\
\text { Asian } \\
\text { American }\end{array}$ & $\begin{array}{c}\text { Black or } \\
\text { African } \\
\text { American }\end{array}$ & White & $\begin{array}{c}\text { Hispanic } \\
\text { or } \\
\text { Latino }\end{array}$ & $\begin{array}{c}\text { Other / } \\
\text { Refused }^{2}\end{array}$ \\
\hline 6 & 0 & 1 & 0 & 1 & 0 & 0 & 0 & 0 \\
\hline 7 & 6 & 7 & 0 & 3 & 0 & 7 & 0 & 4 \\
\hline 8 & 63 & 52 & 8 & 15 & 14 & 85 & 20 & 19 \\
\hline Total & 69 & 60 & 8 & 19 & 14 & 92 & 20 & 23 \\
\hline $\begin{array}{l}1 \\
\text { Total for race/ethnicity exceeds 137, the total number of participants, because students may have selected } \\
\text { more than one category. }\end{array}$ \\
2 Categories containing fewer than 5\% of the sample are included with other/refused. \\
\hline
\end{tabular}

During the cognitive interviews, the students completed the same instrument as described above for the classroom study. The cognitive interview data collection also included think-aloud and retrospective questioning approaches. After practicing to talk aloud their thoughts while working through an everyday experience, students talked aloud their thoughts as they worked through the tasks. As the student worked, a project staff member recorded observations about the student's interactions with the system, questions that were addressed, and any areas of confusion. The primary goal of the cognitive interviews and classroom data collection was the same: to determine what aspects of engineering practices were being elicited by the two forms of the task. Additional goals of the cognitive interviews were to determine the extent to which the science content in a task might limit the ability of a student to engage in engineering practices and to 
gather information about the usability of the task. Therefore, after completing different sections of the entire task, project staff asked students questions about their responses and the usability of the online task in addition to recording observation notes.

\section{Results}

Parachute appeared near the end of an assessment designed primarily to measure engineering practices. With this placement near the end of the assessment, 18 students did not complete the entire task simply because they had insufficient time to complete all of the items in the instrument, including earlier items that were unrelated to Parachute, due to the time spent on items appearing before Parachute or limited classroom time allotted. We report on the data collected with the 119 students who completed all of the Parachute items. Slightly more than half, $56 \%$, completed the open version and $44 \%$ completed the scaffolded version of the task.

Usability data were collected in a systematic way only for the cognitive interviews as this was one of the goals for the data collection in this setting. The first set of interviews revealed a significant issue with the interface for the scaffolded version of the task. Eight of the 11 students in the first set of cognitive interviews who engaged with the scaffolded version had difficulty understanding how to select the data they wanted to include as evidence to support their answers. In most of these cases, the observer needed to provide an explanation. The interface for the scaffolded version was redesigned as a result of the confusion that students experienced. After the redesign none of the remaining seven students who completed this version demonstrated any sign of confusion and did not ask about the method of responding. Results for the original and revised interface are reported together. There were no issues reported for the usability of the open version of the task.

Data from the cognitive interviews were similar to that collected in classrooms with respect to the types of responses seen but the data differed significantly in other respects, which creates challenges for interpreting the results. A comparison of the length of the responses in the open version of the task in the two settings, for example, indicates that the responses from the cognitive interviews were significantly longer $[F(1,66)=54.19 ; p<.0001]$. But length alone is not indicative of a better response. Most of the responses collected in the cognitive interviews were written using complete sentences while relatively few from the classroom setting were, so at least some of the additional text did not contribute to the quality of the response. However, there was also a significant difference in the performance on the task aligned with the setting. Overall scores on Parachute were significantly higher for students who participated in the cognitive interviews as compared to those in the classroom study for both versions of the task [scaffolded version: $F(1,52)=8.68 ; p<.01$; open version: $F(1,66)=9.10 ; p<.01$ ]. These scores are based solely on the responses that students entered into the online task and are not a reflection of any verbal responses that may have been made in the think-aloud protocol for the cognitive interviews - the source of data was the same for both groups. Several factors are likely to contribute to this difference in overall score including self-selection for participation in the cognitive interviews; motivation of these participants based on the incentives they received; and that a project staff member was observing each student individually throughout the cognitive interview.

The differences in scaffolding and response formats led to some different information about students' abilities being elicited across both methods of data collection. Specifically, all of the responses in the scaffolded versions included design recommendations and supporting 
evidence that were relevant for the design challenge, although not all were creditable.

Conversely, the open version elicited a much wider range of responses, particularly with respect to the supporting evidence as will be described in detail below. The scaffolding in the task channeled students' responses to select from among the information appearing on the screen while the open version lacked that guidance. As a result, the scaffolded version of the task elicits students' ability to select evidence to support their recommendation but does not measure students' ability to engage in argumentation in engineering, a construct that is better measured by the open version of the task.

Fifty-two students completed the scaffolded Parachute task. All of the responses from these students included an attempt at a recommendation and at least one piece of data from the table in the task as evidence to support their recommendation because the task was programmed to prevent students from advancing to the next screen without submitting a response. The response format for both the recommendation and evidence required clicking on fields visible on the screen in the task, channeling the students' attention and responses. And most students, about $85 \%$, were at least partially successful in making an appropriate recommendation based on the parachute they deemed most likely to be ineffective. Slightly more than half of the students included relevant data to receive at least partial credit as evidence in support of the recommendation that was made as can be seen in Table 2 . When scoring the evidence in both versions of the task, one aspect of the rubric considered alignment of the evidence with the recommendation. That is, a student could receive some credit for evidence when an incorrect recommendation was made. This could happen if they misinterpreted the data, for example thinking that the parachute with the longest drop time was least effective, perhaps applying an intuitive rule or misinterpreting drop time as speed.

Table 2: Student Responses to Two Versions of Parachute Task

\begin{tabular}{lcc}
\hline & $\begin{array}{c}\text { Scaffolded } \\
\mathrm{N}=52\end{array}$ & $\begin{array}{c}\text { Open } \\
\mathrm{N}=67\end{array}$ \\
\hline Attempt at recommendation & 52 & 54 \\
\hline Credited recommendation $^{1}$ & $85 \%$ & $74 \%$ \\
\hline Any reference to data & 52 & 15 \\
\hline Credited reference to data $^{1}$ & $58 \%$ & $47 \%$ \\
\hline Attempt at reasoning & $\mathrm{N} / \mathrm{A}$ & 20 \\
\hline Creditable reasoning $^{2}$ & $\mathrm{~N} / \mathrm{A}$ & $55 \%$ \\
\hline${ }^{1}$ Credited responses include all responses that received full or partial credit; $\%$ relative \\
to the number that made any reference to data. \\
${ }^{2}$ Reasoning was evaluated although the task was not intended to elicit or measure this \\
type of response. \% relative to the number that attempted.
\end{tabular}

The open version of the task allowed for greater freedom in responding and that was reflected in the nature of the responses. Initially, we captured the quality of students' responses for the two aspects of a response that were intended to be elicited by the task: recommendation to the group with the parachute deemed to be ineffective to improve their parachute and the evidence used to support that advice. Assuming that students correctly identified the ineffective parachute in the selected response item, the expectation was for students to specifically recommend that the diameter of the parachute canopy and length of the suspension lines be increased. And explicit data points or a description of the trends was expected as evidence for the 
recommendation. When students selected the incorrect parachute, their responses to the open response part were evaluated based on the parachute selected, so here again it was possible to receive credit for the open part of the task without correctly identifying the parachute.

In the open version of the task, 54 of 67 responses, or about $80 \%$, included recommendations targeting the canopy diameter or suspension line length as can be seen in Table 2. Although this is a large percentage, it falls far short of the $100 \%$ of responses in the scaffolded version that provided an even more specific recommendation. A few of the responses in the open version were off task (e.g. "Hola") but most that did not provide an attempt at a recommendation either made an observation or explained how they determined which parachute was ineffective:

\section{The diameter was small}

The travel time was the fastest and the line was one of the shortest causing a greater chance for it to crack.

The parachute with the fastest fall time was probably the ineffective one

Many of the responses provided suggestions for improving the canopy by changing the dimensions of the canopy and/or suspension lines without providing evidence for the recommendation:

Have a slightly wider parachute and more suspension line length.

\section{Something that would improve it is by increasing the canopy diameter}

The expectation for the second part of the open-ended section of the task was to provide evidence to support the recommendation. There was a significant drop in the number of responses that referred to any aspect of the data (e.g. specific data points, trends). Only 15 responses, or $28 \%$ of those that attempted to make a recommendation, made any reference to the data. And slightly fewer than half of those included a level of evidence that could be awarded at least partial credit. The following is an example of a response that includes a recommendation for both canopy diameter and suspension line but evidence only for canopy diameter:

Some recommendations that I would give group five is to first make the canopy's diameter much larger. When you look at the data the bigger the parachute the slower it fell makes it much safer. Another recommendation would be to make the suspension line longer, and in the high forties.

Although many more students who completed the scaffolded version provided evidence for their recommendation than did those in the open version, there is much less difference between the relative number who provided creditable responses compared to those who attempted at $58 \%$ and $47 \%$, respectively. In fact, a chi-square test suggests that compared with students in the 'open group', students in the 'scaffolded group' did not show higher incidence of providing creditable evidence on the task $\left(X^{2}=0.572, \mathrm{p}=0.449\right)$ when controlling for responses that made any reference to the data. Therefore, the scaffolding guided students to know what it meant to provide evidence but did not have an impact on the quality of the evidence they provided to support their recommendation. Those who completed the open version of the task needed to understand that general references to the data provided are insufficient to be considered evidence 
for a recommendation (e.g. Have longer/bigger of everything, because it seems to be much more effective than the shorter lines).

We noticed that a significant number of responses provided conceptual reasoning rather than, or in addition to, evidence to support the recommendation about the parachute design. In fact, more students provided conceptual reasoning than evidence in their responses (Table 2), a result we found surprising because this task was not intended to elicit this type of response. We wanted to capture these responses because it indicates that students misunderstand evidence in this context, we revised the scoring rubrics to capture these responses. The reasoning most often referred to air resistance or drag:

I would have recommended them to add to the diameter of the canopy because that would increase the amount of drag and it would slow down the load and safely carry it down.

The canopy diameter of $30 \mathrm{~cm}$ was pretty small for a parachute. The bigger the diameter the more air resistance there would be and the slower the container would have fell. If you look at group 5 travel time, it was pretty fast compared to the others. (Response includes conceptual explanation and evidence.)

Reasoning was not explicitly requested in the task, so although it is reasonable and, we might argue, an expectation that a design recommendation include both evidence and reasoning this was not a measurement goal for this task. Given the relatively recent adoption of NGSS by New Jersey, we did not expect students or teachers to be very familiar with engineering and argumentation practices that would have students include evidence and reasoning without prompting them for these components of a response. The task explicitly directs students to include evidence for their design recommendation but lacks any mention of reasoning. Table 2 shows that more students attempted and were credited for a conceptual explanation than for evidence supporting their recommendations, an aspect of the construct that cannot be measured using the existing form of the scaffolded task.

A closer look at these data, focusing on the types of responses provided in the open version of the task across the two settings (cognitive interview vs. classroom data collection) suggests that the nature of the responses may have been impacted by the setting in which the data were collected. As mentioned earlier, students participating in the cognitive interviews had significantly higher scores on the overall task than those who completed the task in a classroom setting, which is not surprising given the self-selection, motivation, and close attention paid to the students by project staff. But we did not expect to see a systematic difference in the nature of the responses in the two settings. The proportion of responses collected in the classroom setting that included reasoning is equivalent to that for evidence. By contrast, about twice as many responses collected in the cognitive interviews included reasoning as compared to evidence as shown in Table 3.

A possible factor that may contribute to these apparent differences in response types in the two settings is the students' preconceived notions of the types of responses expected in a cognitive interview. Slightly more than half of the students participating in the cognitive interviews were recruited through an ETS intranet site and many of these students had prior experience as participants in cognitive interview studies for other research projects. They are likely to be more practiced in providing reasons when responding in assessment tasks as that is 
often a key goal for conducting these studies and that explanation is shared with students. In fact, a major reason for conducting some of the interviews in schools was to increase our confidence that students who participated in the cognitive interviews were more representative of those in the schools in this region than we might typically engage in a cognitive interview study.

Table 3: Comparison of Two Settings for Open Version of Parachute Task

\begin{tabular}{lcc}
\hline & $\begin{array}{c}\text { Cognitive } \\
\text { Interview } \\
\mathrm{n}=18\end{array}$ & $\begin{array}{c}\text { Classroom } \\
\mathrm{n}=49\end{array}$ \\
\hline Attempt at recommendation & $18(100 \%)$ & $36(73 \%)$ \\
\hline Credited recommendation ${ }^{1}$ & $83 \%$ & $78 \%$ \\
\hline Any reference to data & $5(28 \%)$ & $10(20 \%)$ \\
\hline Credited reference to data ${ }^{1}$ & $80 \%$ & $40 \%$ \\
\hline Attempt at reasoning & $91 \%$ & $11 \%$ \\
\hline Creditable reasoning & \\
\hline${ }^{1}$ Credited responses include all responses that received full or partial credit; $\%$ relative \\
to the number that made any reference to data. \\
${ }^{2}$ Reasoning was evaluated although the task was not intended to elicit or measure this \\
type of response. \% relative to the number that attempted.
\end{tabular}

We anticipated that scoring responses from a scaffolded version of the task would be easier and take less time than responses from an open version, but our limited observations suggest otherwise, at least for this initial administration of Parachute. While we did not systematically record the amount of time raters spent on scoring the two tasks, several observations reflect the relatively more challenging than expected nature of scoring responses for the scaffolded version. A single training session was required to prepare raters for scoring the responses to the open version and scoring was completed in much less than a day. After the initial training for the scaffolded version, a calibration exercise with raters indicated significant disagreement on interpreting evidence provided in the responses. A graphic organizer was then created to be used in conjunction with the rubric to facilitate scoring. A second training was conducted and two discussion sessions were held to address different interpretations of evidence. The cognitive load for scoring these responses required considerable concentration and raters reported needing more time to ramp up to scoring responses. Finally, when one of the raters was informed that a new project would be using Parachute and he would be scoring responses, he was relieved to hear that only the open version of the task would be used.

In addition to being unsystematic in their collection, these observations about scoring are insufficient to make a conclusion about a comparison regarding the resources required for the two versions. First, most of the text responses in the open version of the task were limited to making a recommendation. Lacking evidence or reasoning, the responses were much easier to score than would be expected and therefore they took very little time. By contrast, all of the responses in the scaffolded version of the task included evidence. This version of the task made it so easy for students to provide evidence that, in some cases, they selected eight or more pieces of evidence for each dimension of the parachute: the canopy diameter and suspension line length. Raters needed to determine whether the evidence supported the student's recommendation about redesigning the parachute and how strong the evidence was. If this task was to be administered as part of a large scale assessment, automated scoring would be a likely approach. In that case, 
we would expect the effort related to scoring would be opposite what we observed here; that is, the scaffolded version would require fewer resources because it would not involve scoring text responses. A logic model would be created and programmed that could easily score the responses in the scaffolded version. A draft version of that model was created in conjunction with discussions related to this study. By contrast, colleagues with expertise in automated scoring of constructed-response items have indicated that the complexity of a complete answer to the main question in the open version of the task as it appeared here would preclude using existing approaches for automated scoring. The difficulty of parsing and evaluating the multiple parts in a single response: a recommendation for multiple components of the parachute; evidence to support that recommendation; and discounting any reasoning that was provided, would significantly impact the reliability of the scoring model.

\section{Discussion and Future Work}

Ask middle-school students to recommend their favorite app, musical group or movie and they naturally provide at least one reason if not a list of reasons and maybe even some evidence to support that recommendation. But ask a student to make a design recommendation in an assessment task and our study shows that the entire response is likely to consist of "make the canopy bigger" even when they are asked explicitly to provide evidence to support their recommendation. In assessment situations such as this, when students do not include evidence or an explanation even when they are capable of doing so, it limits our ability to accurately portray student knowledge and skills. It is understandable, then, that assessment tasks are often scaffolded to elicit evidence of student knowledge and skills when it is likely that students will not otherwise provide a more complete response. However, results from this study also show that scaffolding an assessment task can have an impact on the construct being measured. By channeling the task and the response format in the Parachute task, for example, we do not learn if students know what it means to provide supporting evidence for a design recommendation and therefore we are less able to measure their abilities with respect to engineering and science practices.

Data and individual student responses from this study coupled with a close review of the two forms of Parachute suggest that they target different aspects of the construct. Channeling or scaffolding students to select from specific options for the recommendation and evidence focuses the task on the ability to interpret and analyze data. By contrast, the open version of the task includes that aspect of the construct and is extended to include a measure of engaging in the practice of argumentation in an engineering context: critiquing alternative designs, drawing upon knowledge of engineering concepts and science practices to support a design recommendation.

Scaffolding is also often recommended to reduce the cost associated with scoring responses. We did not intend to explore the question of staff hours (cost) associated with human scoring the responses, however, for this small study there were noticeably more staff hours associated with scoring the responses to the scaffolded version of the Parachute task than the open version due to the complexity of the scoring rubric. If this were to be scaled up, an algorithm could be written to program an automated scoring system that would eliminate the need for human scoring of the scaffolded version of the Parachute task. Although this would require a significant upfront investment of time on the part of technical staff and a system to carry out the scoring activity, the cost per scored response would decrease dramatically with a large number of responses as has been reported by Topol et al. [6]. 
Limitations of the study include the focus on a narrow segment of science and engineering practices and an equally narrow range of scaffolding types. These data can provide only a glimpse into the impact of scaffolding in assessments and are not generalizable to other situations, including other engineering practices or other types of scaffolding. Reflecting on the results obtained here, we can imagine different approaches to scaffolding that might allow us to capture a broader range of engineering practices, including those considered in this study.

There may be several avenues that take various middle-ground approaches to this issue of balancing the desire to optimize measurement of complex practices such as those identified in the NGSS and the need to minimize the cost of scoring responses in large-scale assessments. We expect to explore alternatives that will make use of technology to scaffold open versions of similar types of tasks that are less constraining on our measurement of the construct. At the same time, we would strive to focus the text-based responses to allow for more accurate automated scoring than would be possible with a completely open response field and less costly option than human scoring. For example, we could ask students to critique a set of designs such as those in this study and to write a recommendation for improving or selecting a design, without the added directive to include evidence to support their answer. After the response is submitted online, a series of follow-up items could have students reflect on their response and provide additional information as appropriate. While this approach might utilize automated scoring of text responses, it would not require responses to be evaluated in real time. We hypothesize that using focused follow-up items and technology enhancements, such as highlighting within the response would reduce the complexity of the text that is being scored in each component of the task thereby increasing the accuracy of the automated scoring and perhaps eliminating the need for human scoring. This approach also seems to have the potential to obtain a more valid picture of students' abilities with respect to the practices.

\section{Acknowledgment}

We thank Dr. Shuangshuang Liu for her statistical expertise and Dr. Leslie Nabors Olah for her careful review of an earlier version of this paper and her suggestions.

\section{References}

[1] C. Sneider and Ş. Purzer, "The rising profile of STEM literacy through national standards and assessments," in Engineering in pre-college settings, S, Purzer, J. Strobel, and M. Cardella, Eds. West Lafayette, IN: Purdue University Press, 2014, pp. 3-19.

[2] W. R. Penuel, C. J. Harris, and A. H. DeBarger, "Implementing the Next Generation Science Standards". Kappan, vol. 96, no. 6, pp. 45-49, 2015.

[3] National Research Council (NRC), Developing Assessments for the Next Generation Science Standards. Committee on Developing Assessments of Science Proficiency in K-12. Board on Testing and Assessment and Board on Science Education, J.W. Pellegrino, M.R. Wilson, J.A. Koenig, and A.S. Beatty, Editors, Division of Behavioral and Social Sciences and Education. Washington, DC: The National Academies Press, 2014.

[4] J. W. Pellegrino, "Proficiency in science: Assessment challenges and opportunities," Science, vol. 340, no. 6130, pp. 320-323, July 19, 2013. Accessed at http://science.sciencemag.org/content/sci/340/6130/320.full.pdf

[5] B. Topol, J. Olson, and E. Roeber, "The cost of new higher quality assessments: A comprehensive analysis of the potential costs for future state assessments," Stanford, CA: Stanford University, Stanford Center for Opportunity Policy in Education, 2010. 
[6] B. Topol, J. Olson, E. Roeber, and P. Hennon, "Getting to higher-quality assessments: Evaluating costs, benefits, and investment strategies," Stanford, CA: Stanford University, Stanford Center for Opportunity Policy in Education, 2013.

[7] R. D. Pea, "The social and technological dimensions of scaffolding and related theoretical concepts for learning, education, and human activity," The Journal of the Learning Sciences, vol. 13, no. 3, pp. 423-451, 2004.

[8] D. Wood, J. S. Bruner, and G. Ross, "The role of tutoring in problem solving," Journal of Child Psychology and Psychiatry, vol 17, pp. 89-100, 1976.

[9] K. L. Cho and D. H. Jonassen, "The effects of argumentation scaffolds on argumentation and problem solving," Educational Technology Research and Development, vol. 50, no. 3, pp. 5-22, 2002.

[10] C. Quintana, B. J. Reiser, E. A. Davis, J. Krajcik, E. Fretz, R. G. Duncan, E. Kyza, D. Edelson and E. Soloway, "A scaffolding design framework for software to support science inquiry," The Journal of the Learning Sciences, vol. 13, no. 3, pp. 337-386, 2004.

[11] I. Tabak, "Synergy: A complement to emerging patterns of distributed scaffolding," The Journal of the Learning Sciences, vol. 13, no. 3, pp. 305-335, 2004.

[12] B. J. Reiser, "Scaffolding complex learning: The mechanisms of structuring and problematizing student work," The Journal of the Learning Sciences, vol. 13, no. 3, pp. 273-304, 2004.

[13] H. Kang, J. Thompson, M. Windschitl, "Creating Opportunities for Students to Show What They Know: The Role of Scaffolding in Assessment Tasks," Science Education, vol. 98, no. 4, pp. 674-704, 2014.

[14] National Research Council (NRC), A framework for K-12 science education: Practices, crosscutting concepts, and core ideas, The National Academies Press, Washington, DC. 2012.

[15] R. J. Mislevy and G. D. Haertel, "Implications of evidence-centered design for educational testing," Educational Measurement: Issues and Practices, vol. 25, no. 4, pp. 6-20, Winter 2006.

[16] E. S. Quellmalz, M. J. Timms, M. D. Silberglitt, and B. C. Buckley, "Science assessments for all: Integrating science simulations into balanced state science assessment systems," Journal of Research in Science Teaching, vol. 49, no. 3, pp 363-393, 2012. 


\section{Appendix: Parachute Task}

Figure 2: Screen 1 of the scaffolded version of the task.

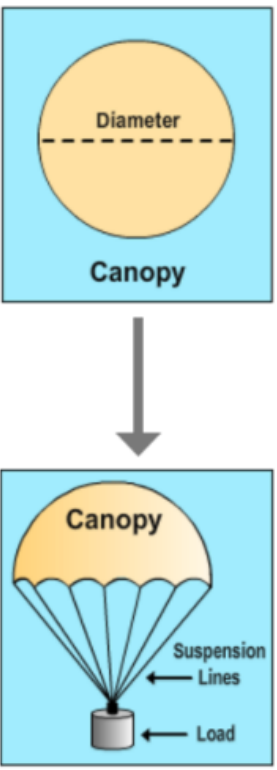

Parachute

Groups of students designed, created, and tested a prototype parachute that was required to safely carry a small, heavy object in a plastic case to the ground. Data for five of the groups' parachutes and their performances are shown in the table below. The design of one of the parachutes was not effective, and the plastic case cracked when the case and parachute landed

Which group most likely had the ineffective parachute? Click on the group number on the table to highlight the row in the table for that parachute.

\begin{tabular}{|c|c|c|c|c|}
\hline Group & $\begin{array}{c}\text { Canopy Diameter } \\
(\mathrm{cm})\end{array}$ & $\begin{array}{c}\text { Suspension Line Length } \\
(\mathrm{cm})\end{array}$ & $\begin{array}{c}\text { Distance Dropped } \\
(\mathrm{m})\end{array}$ & $\begin{array}{c}\text { Travel Time } \\
\text { (launch to landing) } \\
(\mathrm{s})\end{array}$ \\
\hline 1 & 36 & 49 & 5.5 & 6.1 \\
\hline 2 & 41 & 46 & 5.5 & 6.8 \\
\hline 3 & 45 & 48 & 5.5 & 7.0 \\
\hline 4 & 36 & 36 & 5.5 & 5.0 \\
\hline 5 & 30 & 36 & 5.5 & 4.1 \\
\hline
\end{tabular}

Figure 3: Screen 2 of the scaffolded version of the task.

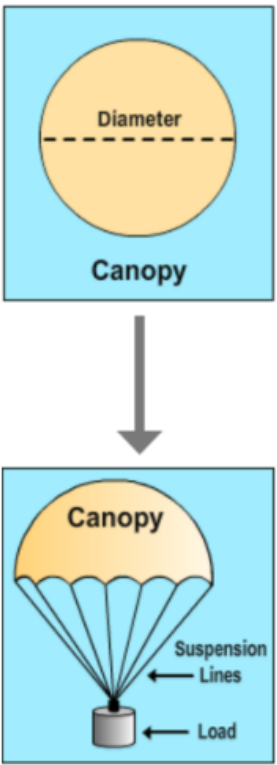

\section{Parachute}

Groups of students designed, created, and tested a prototype parachute that was required to safely carry a small, heavy object in a plastic case to the ground. Data for five of the groups' parachutes and their performances are shown in the table below. The design of one of the parachutes was not effective, and the plastic case cracked when the case and parachute landed.

What advice would you provide to the group whose parachute needs the most improvement so they can redesign their parachute to be more effective? (Select one option from each column below.)

$\begin{array}{ll}\text { Canopy diameter } & \text { Suspension line length } \\ \text { Increase } & \text { Increase } \\ \text { Decrease } & \text { Decrease } \\ \text { Keep it the same } & \text { Keep it the same } \\ \text { Doesn't matter } & \text { Doesn't matter }\end{array}$

\begin{tabular}{|c|c|c|c|c|}
\hline Group & $\begin{array}{c}\text { Canopy Diameter } \\
(\mathrm{cm})\end{array}$ & $\begin{array}{c}\text { Suspension Line Length } \\
(\mathrm{cm})\end{array}$ & $\begin{array}{c}\text { Distance Dropped } \\
(\mathrm{m})\end{array}$ & $\begin{array}{c}\text { Travel Time } \\
(\text { launch to landing) } \\
(\mathrm{s})\end{array}$ \\
\hline 1 & 36 & 49 & 5.5 & 6.1 \\
\hline 2 & 41 & 46 & 5.5 & 6.8 \\
\hline 3 & 45 & 48 & 5.5 & 7.0 \\
\hline 4 & 36 & 36 & 5.5 & 5.0 \\
\hline 5 & 30 & 36 & 5.5 & 4.1 \\
\hline
\end{tabular}


Figure 4: Screens 3 and 4 of the scaffolded version of the task; evidence for canopy diameter and suspension line length was elicited on separate screens.

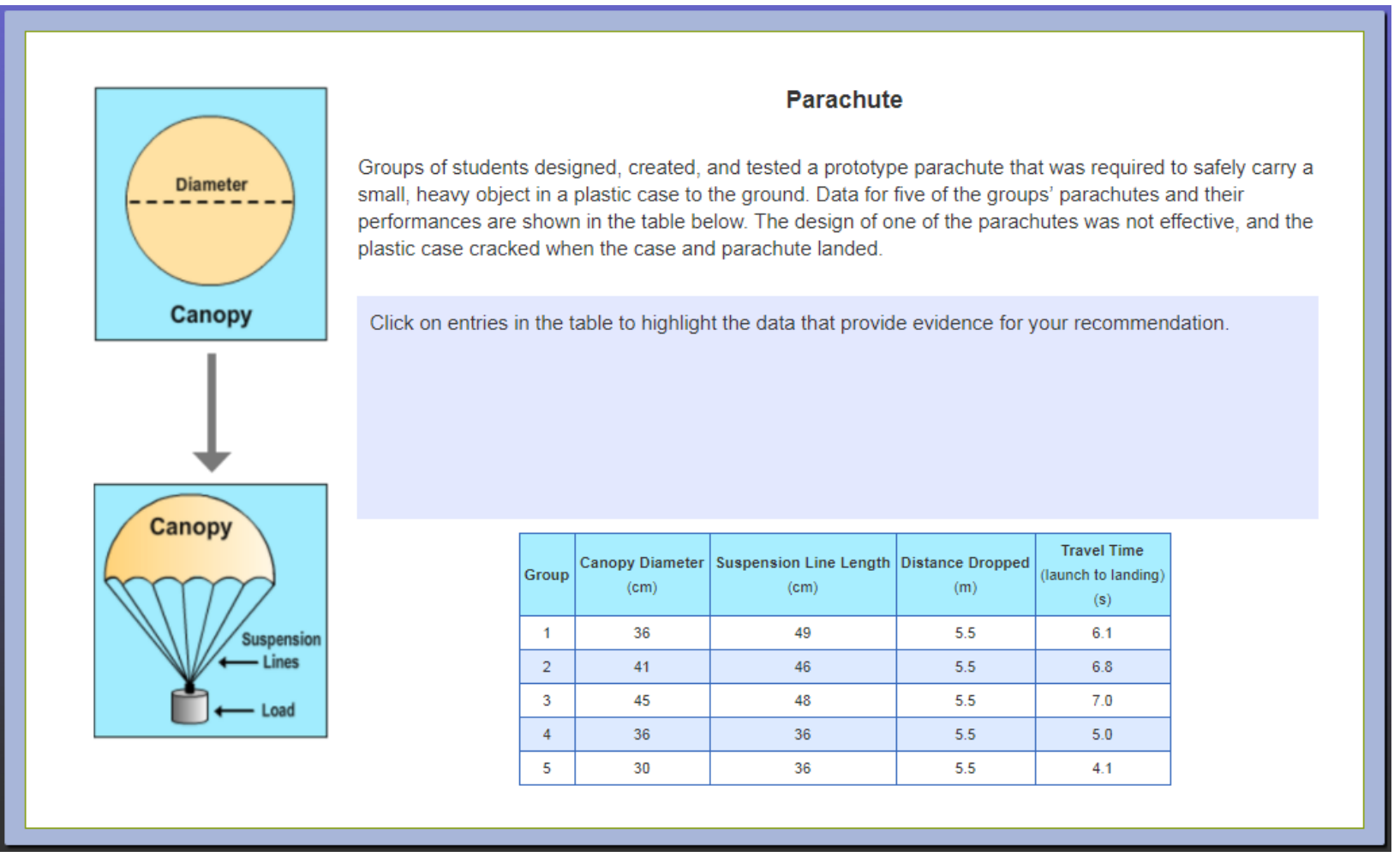

Figure 5: Only screen for the open version of the task.

Groups of students designed, created, and tested a prototype parachute that was required to safely carry a small, heavy object in a plastic case to the ground. Data for five of the groups' parachutes and their performances are shown in the table below.

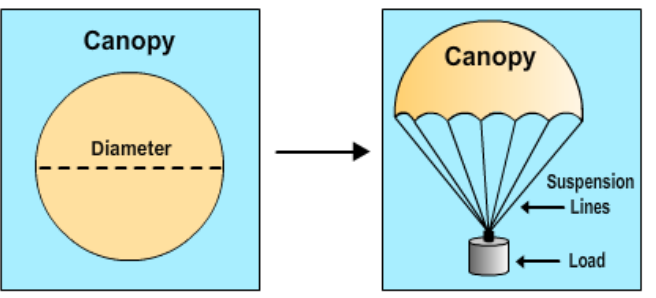

\begin{tabular}{|c|c|c|c|c|}
\hline Group & $\begin{array}{c}\text { Canopy Diameter } \\
(\mathrm{cm})\end{array}$ & $\begin{array}{c}\text { Suspension Line Length } \\
(\mathrm{cm})\end{array}$ & $\begin{array}{c}\text { Distance Dropped } \\
(\mathrm{m})\end{array}$ & $\begin{array}{c}\text { Travel Time } \\
\text { (launch to landing) } \\
(\mathrm{s})\end{array}$ \\
\hline 1 & 36 & 49 & 5.5 & 6.1 \\
\hline 2 & 41 & 46 & 5.5 & 6.8 \\
\hline 3 & 45 & 48 & 5.5 & 7.0 \\
\hline 4 & 36 & 36 & 5.5 & 5.0 \\
\hline 5 & 30 & 36 & 5.5 & 4.1 \\
\hline
\end{tabular}

The design of one of the parachutes was not effective, and the plastic case cracked when the case and parachute landed.

Which group most likely had the ineffective parachute?

\section{$\Gamma$}

Write a recommendation to that group to provide them with suggestions for improving their parachute. Provide convincing evidence to support your recommendation.

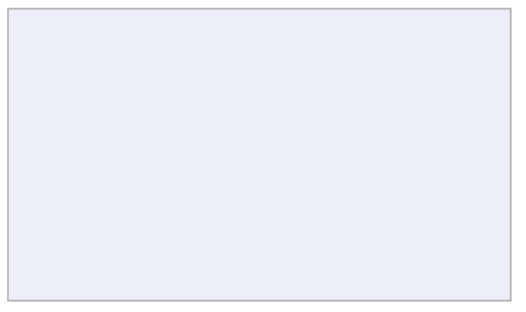

